\title{
A Study on the Construction of Ideological and Political Theory Course in Universities Based on MOOC
}

\author{
Peng Liusheng \\ Hunan Vocational College of Modern Logistics, Changsha, 410131, China
}

Keywords: ideological and political theory course; MOOC platform; course construction

\begin{abstract}
While the MOOC platform has provided enormous opportunities for higher education in the world, it also has posed a great challenge to China's education. This study first introduces that the teaching mode based on MOOC is consistent with the connotation of ideological and political education. Based on the necessity of applying this new teaching platform to the ideological and political theory course in universities, this study sums up the problems confronting the ideological and political theory course in universities based on MOOC. Finally, this study puts forward measures to construct the ideological and political theory course MOOC platform so as to improve the efficiency of teaching and develop core socialist values.
\end{abstract}

\section{Introduction}

MOOC is a new teaching mode emerged in the era of big data, and we cannot deny the major role played by this teaching mode in innovation.[1] Following the development path of the reform on course teaching, the emergence and rise of MOOC is obviously a significant milestone.[2] Therefore, in the face of the reform caused by MOOC, ideological and political education in universities should "take advantage of the situation", adopting a positive attitude to explore new ways of combining itself with the teaching mode based on MOOC.

\section{The Teaching Mode Based on MOOC Being Consistent with the Connotation of Ideological and Political Education}

The ideological and political course in universities is the external manifestation of the connotation of ideological and political education, and thus any innovation of the course should be consistent with the connotation. Based on the features of the connotation, ideological and political education places more emphasis on the truth of educational thoughts and the scientificalness of methods and means. [3] On the one hand, MOOC, as the latest method of information-based teaching in the era of big data, precisely meets the demand on the scientificalness. [4] On the other hand, large-scale open online teaching has wider coverage, more audience, and greater influence on social members than traditional classroom teaching, providing a new path for the spread of ideological and political education. [5] Therefore, the application of MOOC could make the ideological and political course in universities not only serve the higher education, but also play a role in educating other members of society.

\section{The Problems Confronting the Ideological and Political Theory Course in Universities Based on MOOC}

\subsection{Insufficient Importance Attached to the Construction of MOOC}

The Opinions of the Ministry of Education on Strengthening the Application and Management of Online Open Courses in Universities and Colleges clearly states that institutions of higher education shall effectively assume the main responsibility of the application and management of online open courses. [6] However, many universities did not pay enough attention to the construction of MOOC, especially the construction of the ideological and political theory course based on MOOC. Some colleges still take a wait-and-see attitude, even a resistant attitude, to the 
construction of MOOC, and have limited input in human, material and financial resources. The fledging MOOC, yet, requires a lot of human, material, and financial resources. If universities and colleges do not attach sufficient importance to the construction, the investment in various fields will be inevitably limited, let alone build high-quality MOOC.

\subsection{Ideological and Political Theory Course Based on MOOC Lacks High-quality Online Curriculum Resources}

The resources of the ideological and political education could be divided into different categories according to different criteria. From the perspective of sources, they fall into categories like text, audio and video, and network information; from the perspective of generators, books which assist in teaching, such as textbooks and teacher's books, and data resources which are sorted out by teachers at any time for teaching, such as social issues and state policies, are all important component of the resources. In addition, due to the greater flexibility of MOOC, there are richer sources of resources. It is worth noting that the valuable and meaningful generative curriculum resources which can be used for secondary teaching as well as the experience and results gained in the teaching of MOOC can all become a new generation of teaching resources. Being the main factor of course content, curriculum resources are the constant input of fresh blood in teaching activities and the source of teaching materials. Whether the ideological and political theory course is in the form of MOOC or in other forms that may occur in the future, it is inseparable from rich and substantial curriculum resources. Without curriculum resources, all teaching activities could not be carried out, as the resources play a leading and decisive role in the implementation and development of curriculum. However, at present, the update of curriculum resources is not satisfactory. The main reason is that the main role of the two subjects of resource development, teachers and students, are not fully demonstrated.

\subsection{Loose Construction and Management of the Ideological and Political Theory Course MOOC Platform}

MOOC needs to upload, select and organize curriculum resources, and this series of work is conducted on the premise that a good platform is established. Once the MOOC platform lacks rigor, especially blindly follows Western ideological education courses, or lacks an efficient "filtering system" on resources management, it may directly confront crises. On the other hand, the features of MOOC make it more difficult to organize and manage students. The autonomy and organizational learning of MOOC require the subjects to have a relatively high level of learning consciousness. Because of the influence of traditional teaching modes, thinking styles and learning habits, there is a big gap between the quality of subjects in people's expectation and which in reality. However, it is difficult for constructors to provide an effective platform model and thus the platform is prone to management oversight.

\subsection{Functions and Experiences of MOOC Platforms Need to Be Upgraded}

The design of MOOC platforms, including network traffic, platform functionality, and art design, directly affects students' learning experiences. At present, domestic MOOC platforms are just at the outset, with the platform design only meeting the basic needs. Being too sweeping as well as lacking humanization and diversity, current platform design cannot fulfill the various demands of students, such as different learning tasks for learners at different levels, adjustable speed of video playback, and real-time interactive tools. In the survey, the students responded that the platform has poor networks and stalls on video, some guiding functions of the platform are hidden, and the art design of pages need to be improved.

\section{The Construction of the Ideological and Political Theory Course MOOC Platform}

High-quality curriculum resources are the core of MOOC as well as the main content of students' MOOC learning. Therefore, the gathering of the best teaching resources is undoubtedly an important link in constructing the ideological and political theory course MOOC platform, as shown 
in Figure 1.

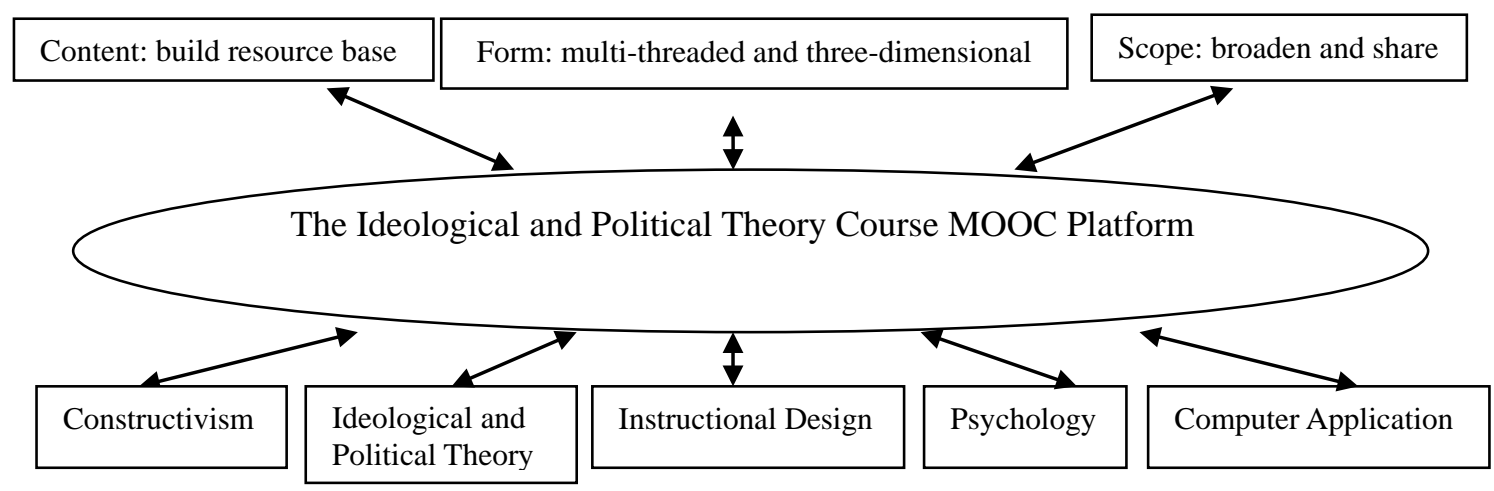

Figure 1 The Ideological and Political Theory Course MOOC Platform

\subsection{Enriching and Assembling, To Build the Ideological and Political Theory Course Resource Base}

With the popularization and improvement of computer multimedia technology and network communication technology in the education field, computer-assisted instruction in universities and colleges has evolved from the production of courseware to the construction of teaching resources base and open teaching websites and teaching resources have been gradually promoted and developed. Many universities and colleges have accumulated teaching resources in terms of their own excellent ideological and political theory courses. However, at present, most of the online courses still simply copy the contents of classroom presentation to the screen, being single in form and monotonous in content. The vitality of the resource base lies in its ability to actively provide students with targeted and valuable information. Therefore, on the basis of established resource bases, the ideological and political theory course based on MOOC should offer as much relevant information as possible to students. The excellent information not only adheres to the classic but also reflects the spirit of the times, forming a scalable and diverse collection of resources. On the one hand, experts and teachers in the field of ideological and political theory courses build a central knowledge base which covers a wide range of humanities and social sciences, such as economy, politics, culture, society, psychology, and philosophy, based on their existing experience. On the other hand, the large amount of useful knowledge produced by experts and teachers in answering students' practical questions should also be easily accessible to learners. The teaching mode based on MOOC puts emphases on assembling such high-quality teaching resources and aims at providing learners with the best experience and a complete set of excellent teaching resources, including learning materials and learning guidance, which can only be owned by first-class experts in first-class universities.

\subsection{Integration and Optimization, To Make the Ideological and Political Theory Course Resources Multi-threaded and Three-dimensional}

The ideological and political theory course based on MOOC uses modern information technology to enrich and reconstruct knowledge, and then applies a brand-new method of knowledge organization. In addition to having the best videos of lectures for students to learn, the teaching mode based on MOOC needs to further integrate the excellent resources of ideological and political theory courses around the country, including a large amount of free reading materials that are open online, to provide students with accurate, complete, efficient, and rich curriculum resources. There materials not only include the core resource of the curriculum, such as books and documents like textbooks, lesson plans, and classics of Marxism as well as the most authoritative and influential newspapers like People's Daily and Guangming Daily, but also contain support resources related to the curriculum, such as network resources, social practice resources, teaching cases, social hotspots, current policy reviews and the related knowledge, experience, feelings, 
confusion, emotional attitudes and values. In each unit of the ideological and political theory course, not only a large number of "situational reading materials" which help students expand their reading and deepen their understanding of each difficulty as well as the overall system but also "make-up reading materials" which make students with "weak foundation” prepare to learn. These materials need to adopt to open, interactive, shared and personalized learning modes through effective integration and overall planning. In this way, students can have a comprehensive understanding of the ideological and political theory course with the guidance of MOOC in a relatively short time.

\subsection{Co-construction and Sharing, Broaden the Scope of the Ideological and Political Theory Course Resources}

The co-construction and sharing of resources refers to the owner co-construct and share the resources with others, and it is the process of the transition from individual ownership to group ownership. At present, universities and colleges build and use ideological and political theory resources according to their own needs and these resources are closed and independent. At the same time, most of these resources are only accessible to their own students, which sets up barriers to sharing. The emergence of the teaching mode based on MOOC makes the sharing of ideological and political theory resources become a reality, providing a rare opportunity to improve the efficiency of the ideological and political theory course. Undoubtedly, elite universities and colleges are an important force in the course, as they integrate a large amount of excellent resources which are of great importance which should not be underestimated to the co-construction and sharing. Thus, all universities an colleges directly managed by the Ministry of Education should take the lead in setting examples, guide and support outstanding teachers to develop MOOC with certain characteristics and influences, promote the opening of high-quality curriculum resources of ideological and political theory course to students in other universities and colleges, and broaden the scope of the resources. In this way, even those schools which are not able to set up or offer high-quality ideological and political theory course due to various factors, such as the quality of faculty, enable the students to directly learn the course on the MOOC platform, which not only saves educational resources but also improves the scope and efficiency of ideological and political education.

\section{Conclusion}

Compared with the traditional teaching mode, the teaching mode based on MOOC is of significant innovation value and enlightenment value. It is necessary for the reform of ideological and political education in universities to incorporate the teaching mode based on MOOC. This study uses the teaching philosophy and technology of MOOC to carry out all-round reforms on the ideological and political theory course in universities from three aspects, enriching resource base, making the content multi-threaded and three-dimensional, and broadening the scope of the resources, and proposes to construct the ideological and political theory course MOOC platform to enable students to gain knowledge, broaden horizon, enhance ability, and perfect personality, so as to truly realize the purpose of ideological and political education.

\section{References}

[1] Curriculum and concept of control. Doll, W.E.Jr. Curriculum: Toward New Identities. 1998

The Year of the MOOC. Laura Pappano. The New York Times. 2012

[2] Teaching entrepreneurship using Massive Open Online Course (MOOC) [J].Mushtak Al-Atabi, Jennifer DeBoer. Technovation . 2014

[3] Watching MOOCs together: investigating co-located MOOC study groups [J]. Nan

[4] Li, Himanshu Verma, Afroditi Skevi, Guillaume Zufferey, Jan Blom, Pierre Dillenbourg. Distance Education. 2014 (2) 
[5] Designing MOOCs for the Support of Multiple Learning Styles. Franka Grunewald, Christoph Meinel. European Conference on Technology Enhanced Learning. 2013

[6] Open courses: one view of the future of online education. Alemi Farrokh, Maddox P J. The Journal of health administration education. 2009 